\title{
POSTERIOR AORTOVENTRICULAR BLEEDING AFTER SUPRA-ANNULAR STENTLESS AORTIC VALVE REPLACEMENT
}

\author{
N. Mediratta, FRCS, A. W. Sosnowski, MD, and M. Galiñanes, MD, PhD, Leicester, United Kingdom
}

Replacement of the aortic valve with stentless xenografts has the advantage of allowing the aortic anulus to follow the cardiac cycle, and it has been suggested that this feature may lead to a faster and more complete regression of myocardial hypertrophy than that seen in patients with stented aortic valve implants. ${ }^{1}$ In addition, the lack of a rigid wire stent and sewing ring allows a larger size of valve to be implanted that also contributes to minimizing the gradient across the aortic anulus. A further benefit is that, because of the absence of nonbiologic material, anticoagulation therapy is not required, even during the early postoperative period. ${ }^{1,2}$

The Cryolife-O'Brien model 300 (Cryolife International, Atlanta, Ga) stentless aortic valve differs from other stentless valve designs in that it is a composite valve, constructed by suturing together three separate noncoronary cusps. This valve has wide coaption of the leaflets, and there is minimal aortic wall above the valve cusps and virtually no tissue below the cusps. A unique implantation technique using a single supra-annular and subcoronary continuous suture line has been described by O'Brien. ${ }^{3}$ The symmetric shape of this composite valve is particularly useful in replacing degenerative calcified aortic valves, which are commonly tricuspid and symmetric. Moreover, the single continuous suture technique helps expedite implantation, which is especially useful for elderly patients and patients with severely impaired left ventricular function, for whom shortening the ischemic period may help in reducing operative myocardial injury and determining outcome.

We have successfully implanted 20 Cryolife-O'Brien stentless aortic valves, using the single suture line technique, and report an unusual complication, encountered by 2 patients, of massive bleeding on resumption of cardiac activity. This bleeding was a result of posterior aortoventricular discontinuity adjacent to the roof of the left atrium.

Patients. A 71-year-old woman with rheumatic aortic and mitral valve disease was referred for surgery. She had features of pulmonary edema, and echocardiography demonstrated

From the Division of Cardiac Surgery, Department of Surgery, University of Leicester, Glenfield Hospital NHS Trust, Leicester, United Kingdom.

Received for publication Dec 8, 1998; accepted for publication Dec 15, 1998.

Address for reprints: Mr N. Mediratta/Mr M. Galiñanes, Division of Cardiac Surgery, Department of Surgery, University of Leicester, Glenfield Hospital NHS Trust, Groby Road, Leicester, LE3 9QP, United Kingdom.

J Thorac Cardiovasc Surg 1999;117:1031-2

Copyright (C) 1999 by Mosby, Inc.

$0022-5223 / 99 \$ 8.00+0 \quad \mathbf{1 2 / 5 4 / 9 6 5 2 5}$ mixed aortic stenosis and regurgitation along with mixed mitral stenosis and regurgitation. The anulus was heavily calcified. Angiography revealed normal coronary arteries but a severe impairment of left ventricular function. Her operation was performed with cardiopulmonary bypass through bicaval cannulation and moderate hypothermia. She underwent an aortic valve replacement with a 23-mm Cryolife-O'Brien stentless bioprosthesis, implanted with a single continuous supra-annular and subcoronary suture technique, as previously described, ${ }^{3}$ after the thickened, fused, and calcified aortic valve cusps were radically excised down to the anulus. The mitral valve leaflets were similarly thickened and fused at the commissures, and there was shortening and fusion of the chordae tendineae. This mitral valve was replaced with a 27mm stented bioprosthesis (Mosaic, Medtronic Heart Valves, Minneapolis, Minn). Intraoperative bleeding was encountered, seemingly from the atrioventricular groove. The left atriotomy was then reexplored and the mitral prosthesis explanted. The bleeding appeared to emanate from aortoventricular disruption close to the roof of the left atrium, and this was successfully controlled with pledget-supported 3-0 polypropylene sutures placed from outside the aorta. The mitral prosthesis was reimplanted, and the patient had a satisfactory postoperative recovery.

Another 77-year-old woman with severe exertional dyspnea and degenerative aortic valve disease was referred for surgery. Echocardiography showed intense calcification of the aortic valve leaflets with a mixed picture of stenosis and regurgitation. Her operation was performed with cardiopulmonary bypass and moderate hypothermia, and the tricuspid aortic valve leaflets were thickened, rigid, and heavily calcified. After excision of the leaflets and thorough decalcification of the anulus, a 27-mm Cryolife-O'Brien stentless bioprosthesis was implanted with the single supra-annular and subcoronary continuous suture technique as previously described. ${ }^{3}$ On resumption of cardiac activity, massive bleeding was evident from the posterior aortoventricular territory. This was secured with pledget-supported 3-0 polypropylene sutures placed from outside the aorta, and the patient's postoperative recovery was uneventful.

Comments. Radical excision of the diseased native aortic valve is essential during valve replacement, particularly when an aortic prosthesis is implanted in a supra-annular position. In both of our cases, this resulted in a weakening of the aortoventricular area in the same position, adjacent to the roof of the left atrium, which led to operative bleeding. In both cases the problem was identified and hemostasis was successfully achieved by placing additional sutures from outside the aorta without the need for internal inspection of the aortic root. 
With the unique single outflow suture line technique, as described by O'Brien, ${ }^{3}$ the continuous suture is placed in a supra-annular position and no sutures pass through the anulus. In conventional stentless valve replacement, with the double suture line technique, ${ }^{1,4}$ a row of inflow sutures pass through the anulus. This absence of support from annular sutures with the O'Brien technique may explain why aortoventricular disruption occurred in these 2 cases weakened by extensive decalcification.

In the 2 cases presented the bleeding occurred before the cessation of cardiopulmonary bypass, on the resumption of cardiac activity. In this scenario, the identification of the bleeding point and securing control was achieved without further consequences. But the bleeding might have occurred later, during the postoperative period, when recognition of the site of bleeding may have been difficult and the situation potentially life threatening.

The first patient underwent concomitant mitral valve replacement surgery with intraoperative hemorrhage, where the exact site of bleeding initially proved difficult to locate. A misdiagnosis was made of disruption of the atrioventricular groove, necessitating reexploration through the left atriotomy and removal of the mitral prosthesis in an attempt to achieve control. After our experience with these 2 cases, we routine- ly reinforce the anulus with interrupted 4-0 Ethibond sutures (Ethicon Ltd, UK) after extensive decalcification. Because these reinforcing sutures are placed at anulus level, and therefore sit below the continuous subcoronary suture line, it is necessary to ensure that the knots make no contact with the leaflets of the prosthetic valve.

Conclusion. Our 2 cases highlight a potential hazard of the single suture line technique when radical debridement of valve leaflets may weaken the anulus. If that occurs, we advocate preemptive reinforcement with interrupted annular sutures.

\section{REFERENCES}

1. Westaby S, Amarasena N, Long V, et al. Time-related hemodynamic changes after aortic replacement with the Freestyle stentless xenograft. Ann Thorac Surg 1995;60:1633-9.

2. Westaby S, Jin XY, Katsumata T, et al. Valve replacement with a stentless bioprosthesis: versatility of the porcine aortic root. J Thorac Cardiovasc Surg 1998;116:477-84.

3. O'Brien MF. The Cryolife-O'Brien composite aortic stentless xenograft: surgical technique of implantation. Ann Thorac Surg 1995;60:S410-3.

4. Kon ND, Westaby S, Amarasena N, et al. Comparison of implantation techniques using Freestyle stentless porcine aortic valve. Ann Thorac Surg 1995;59:857-62. 